\title{
Functional changes in reef systems in warmer seas: asymmetrical effects of altered grazing by a widespread crustacean mesograzer
}

Ryan M. Pearson*1, Kristin I. Jinks ${ }^{1}$, Christopher J. Brown², Thomas A. Schlacher ${ }^{3}$, Rod M. Connolly ${ }^{1}$

${ }^{1}$ Australian Rivers Institute - Coast \& Estuaries, and School of Environment \& Science, Griffith University, Gold Coast, Queensland 4222, Australia

${ }^{2}$ Australian Rivers Institute, Griffith University, Nathan, Queensland 4111, Australia

${ }^{3}$ The ANIMAL Research Centre; University of the Sunshine Coast, Maroochydore DC, Queensland 4558, Australia

Keywords: climate change; ecosystem function; coral reefs; temperate reefs; Clibanarius virescens; crustacean mesograzer

*Corresponding author contact details:

Phone: +61 404007348

E-mail: ryan.pearson2@griffithuni.edu.au

Address: School of Environment \& Science, Gold Coast Campus, Griffith University, Parklands Drive, Southport, QLD, Australia, 4222

Other author e-mail addresses:

K. Jinks: kristin.jinks@griffithuni.edu.au; C. Brown: chris.brown@griffith.edu.au;

T. Schlacher: tschlach@usc.edu.au; R. Connolly: r.connolly@griffith.edu.au

\section{Author contributions}

RMP, RMC, and KIJ designed the study and methodology. RMP led data collection, analysis and writing of the manuscript. All authors contributed critically to analysis, interpretation of results and drafting of the manuscript.

\section{Highlights:}

1. Warmer seas may alter species interactions and ecological functions (e.g. grazing)

2. We measured grazing response in the lab and modelled changes under future climates

3. Grazing changes unimodally with temperature and may increase in Indo-Pacific

4. Small decreases in tropics offset by big increases at higher latitudes in the future

5. Similar responses in other grazers suggest possible broad effects as seas warm 


\begin{abstract}
1 Grazing is a pivotal function in many marine systems, conferring resilience to coral reefs by

2 limiting algal overgrowth, but triggering phase shifts on temperate reefs. Thus, changes to

3 consumption rates of grazing species in response to higher future temperatures may have

4 broad ecological consequences. We measured how the consumption rates of a widespread

5 mesograzer (the hermit crab Clibanarius virescens) responded to changing temperatures in

6 the laboratory and applied these findings to model the spatial footprint on grazing animals

7 throughout the Indo-Pacific region under climate change scenarios. We show that mean

8 grazing capacity may increase in shallow coastal areas in the second half of the century. The

9 effects are, however, asymmetrical, with tropical reefs predicted to experience slightly

10 diminished grazing whilst reefs at higher latitudes will be grazed substantially more. Our

11 findings suggest that assessments of the effects of climate change on reef ecosystems should

12 consider how warming affects grazing performance when predicting wider ecological

13 impacts.
\end{abstract}


Marine ecosystems are increasingly affected by a suite of stressors (Boyd et al., 2015,

Hoegh-Guldberg et al., 2007) which may interfere with important ecological processes that contribute to ecosystem resilience (Bellwood et al., 2003, Hoegh-Guldberg \& Bruno, 2010, Mumby et al., 2007). Surplus nutrients can lead to excessive algal growth and cause some ecosystems (e.g. coral reefs) to undergo phase shifts to alternative states, upsetting trophic structure and reducing biodiversity (Hempson et al., 2018). However, the functional roles of certain consumer groups can help ecosystems resist such changes (Goldenberg et al., 2018). Grazers, for example, exert strong top-down control on the abundance of primary producers in all benthic marine habitats (Poore et al., 2012), which can mitigate the effect of algal blooms (e.g. in coral reefs (Hughes et al., 2007) and rocky shores (Worm \& Lotze, 2006)), in effect increasing ecosystem resilience via resistance to phase shifts (e.g. from coral to algal dominated systems (Mumby et al., 2007)). The effect of grazers on primary producer abundance is strong globally, with both macrograzers and mesograzers (which are generally less recognised as ecosystem engineers) exerting strong control over algal biomass across most marine habitats (Poore et al., 2012). In temperate reefs, which are generally algae dominated, high grazing capacity may have the opposite effect and actually trigger phase shifts (Bennett et al., 2015), sometimes rapidly in response to even short term temperature changes (Wernberg et al., 2016). However, the process of grazing may also be affected by disturbance itself.

Various stressors (e.g. acidification, eutrophication, temperature rise) are known to alter grazer biomass and/or consumption rates (Boyer et al., 2004, Mumby et al., 2006, Wernberg et al., 2016) These stressors can trigger broad changes to ecological function (Hoegh- 
species (Perez et al., 2016). As such, temperature plays a role in defining species distributions (Lancaster, 2016), with strong predictive capacity for identifying the latitudinal range of both tropical and temperate marine species (Poloczanska et al., 2013, Stuart-Smith et al., 2017). Changes in temperature can trigger behavioral responses within the distribution (Briffa et al., 2013, Poloczanska et al., 2013), in some cases altering the feeding and metabolic rates (Fussmann et al., 2014, Rall et al., 2010). The shape of the relationship between grazing rates and temperature within the range of a species is a pivotal variable in predicting how rising sea temperatures will impact ecological functions. The simplest model would suggest that feeding rates rise in a linear fashion with temperature (e.g. Elner, 1980, Smith, 2008), probably resulting from faster metabolism at higher temperatures (Fussmann et al., 2014, Rall et al., 2010). However, the shape of the relationship cannot be truly linear because feeding rates will plateau or decline as temperatures approach physiological tolerance limits (Newell \& Branch, 1980). Thus, it is plausible, if not likely, that the functional response to rising temperature is unimodal (hump shaped).

It follows that rising sea temperatures may increase grazing performance only if the temperature change corresponds or approaches the peak behavioral response. Conversely, temperature beyond the peak behavioral response point will result in lower consumption rates. Understanding this relationship, especially where peak grazing occurs and how rapidly it declines at sub-optimal temperatures may support predictions of ecosystem responses to climate warming. Field studies can rarely manipulate temperatures sufficiently to identify end-points (for both ethical and practical reasons), whereas this is possible in the laboratory. Thus, we opted to test the effect of temperature on feeding rates under controlled laboratory conditions using a common shallow-water mesograzer, the yellow-footed hermit crab (Clibanarius virescens (Kraus, 1843)). This crab is widely distributed across a broad latitudinal range (approx. $\mathrm{N} 37^{\circ}$ to $\mathrm{S} 37^{\circ}$ ) in low intertidal and shallow subtidal habitats 
throughout the tropical and warm temperate Indo-West Pacific (Dunbar, 2005, Kunze \& Anderson, 1979, Morgan, 1988), and is possibly the most diffusely distributed hermit crab in the region (Lewinsohn, 1982). These crabs have shown demonstrable physiological responses to temperature changes (e.g. respiration rate increases with temperature (Dunbar, 2005)), that are consistent with the metabolic theory of ecology. This theory suggests that body size and temperature induce predictable effects on metabolic rate and resource uptake that are relatively consistent across taxa (Brown et al., 2004). Thus, if measurable changes to the grazing capacity of these widespread mesograzers are indicative of similar effects on other consumers, this could suggest concurrent wide-ranging changes to grazing in coastal ecosystems.

Here we quantify the shape of the grazing-temperature response of a widespread shallow water mesograzer (C. virescens), and model how climate change may affect its contribution to this important ecosystem function. We do this first by establishing the effect of temperature on the feeding and behavior of $C$. virescens in the laboratory. We then estimate the effect of climate change (temperature rise) by applying these findings to model potential changes in grazing performance throughout the present distribution of $C$. virescens under two climate change scenarios - RCP 4.5 and RCP 8.5 (Moss et al., 2010, NOAA/ESRL Physical Sciences Division, 2018) across two yearly periods: January to March (JFM); and July to September (JAS).

\section{Material and Methods}

We measured grazing rate of the yellow-footed hermit crab in the laboratory across temperatures between $23^{\circ} \mathrm{C}$ and $38^{\circ} \mathrm{C}$. Crabs were collected from shallow water at low tide at Burleigh Heads, Queensland, Australia (S $28^{\circ} 5^{\prime} 21^{\prime \prime}$, E $\left.153^{\circ} 27^{\prime} 18^{\prime \prime}\right)$ on multiple occasions in the months leading up to an acclimation period. They were then acclimatised to the 
laboratory conditions and feeding schedule for at least three months prior to inclusion in these experiments. Monthly average sea surface temperatures (SST) in the region range between $21.4^{\circ} \mathrm{C}$ in August, to $27.1^{\circ} \mathrm{C}$ in February (World Sea Temperature, 2018). Crabs were kept in aquaria at constant $23^{\circ} \mathrm{C}$, under a 12 hour light/dark regime, and on a four day feeding cycle (i.e. crabs were fed the same algal pellets as used in these experiments once every four days). In the morning of the fourth day of each feeding cycle (and prior to feeding), a sub-set of crabs were selected at random (from a pool of approximately 200 total crabs) and placed into individual containers within larger water baths (one bath per temperature treatment). Each water bath contained 10 crabs in individual containers. Given the expectation that crab size may affect consumption rates, crab size was restricted to those with shell volumes between 500 and $1500 \mathrm{~mm}^{3}$ to maintain similar size distributions across all treatments. Shell volume was calculated from height and width measurements and no difference in mean size was observed among levels.

Temperature was increased to one of five experimental levels $\left(23,26,30,34,38^{\circ} \mathrm{C}\right)$ gradually over a six hour period in an effort to mirror daily warming cycles in shallow waters. An additional level above $38^{\circ} \mathrm{C}$ was attempted (target $42^{\circ} \mathrm{C}$ ). However, temperatures between $39-40^{\circ} \mathrm{C}$ elicited a clear stress response, with many crabs exiting their protective shells and moving in an erratic twitching manner and this treatment was therefore abandoned.

In this experiment we simulate the effect of grazing by using algal pellets of a standard size to quantify grazing rates. Thus, after reaching the target temperature, $10 \times 1 \mathrm{~mm}$ algal pellets were provided to each crab (New Life Spectrum AlgaeMAX 1 mm sinking pellets, containing nine types of algae). The number of pellets consumed was recorded after one hour. Sample sizes per level ranged between 30 and 39, for a total of 177 hermit crabs. We note here that because hermit crabs exchange shells it was impracticable to identify individual crabs. Thus, 
we were unable to quantify any potential re-use of individual crabs throughout the experiment beyond ensuring that no crab was included more than once every four days.

The response of grazing rate to temperature was used to develop a model of grazing performance, which we then used to predict grazing performance across the current distribution under recent temperature conditions and two climate change scenarios. Grazing performance was calculated as the consumption rate per individual per hour, represented as a percentage compared with maximum rate defined by the model. Long term sea surface temperature (SST) data $(1981-2010)$ and future predicted SST $(2050-2099)$ for two periods, January to March (JFM) and July to September (JAS) were used to model changes to the grazing performance of subtidal crabs across their range. These two periods were selected because they were the closest representation of the warmest (and coldest) months in each hemisphere available from the pre-determined periods of the source datasets (NOAA/ESRL Physical Sciences Division, 2018). We note here that crabs that feed primarily in intertidal rock-pools (as opposed to subtidally) will likely be exposed to higher temperature fluctuations and thus beyond the scope of available climate models. Hence, our focus is on the subtidal scenario in temperatures similar to observed and future predicted SST.

Historical data were monthly means between 1981 and 2010, averaged across the target months (Reynolds et al., 2002). Future climate projections were from the NOAA Climate Change Web Portal (NOAA/ESRL Physical Sciences Division, 2018), using the average of all models for the RCP4.5 and RCP8.5 warming scenarios (Moss et al., 2010). SST values were extracted for each scenario and period for every $0.5^{\circ}$ lat $\times$ lon and used to model grazing performance at this scale. These data show mean temperatures across the entire distribution between 1981 and 2010 were approximately $27^{\circ} \mathrm{C}$, which could increase to $29.5^{\circ} \mathrm{C}$ under the RCP 8.5 emissions scenario. Per scenario, increases are $1.10^{\circ} \mathrm{C} \pm 0.01^{\circ} \mathrm{C}$ (mean \pm S.E.) RCP4.5 for JFM and $1.11 \pm 0.01^{\circ} \mathrm{C}$ for JAS, and, under RCP8.5 temperature 
increases of $2.08 \pm 0.01{ }^{\circ} \mathrm{C}$ for JAS, and $2.03 \pm 0.01^{\circ} \mathrm{C}$ for JFM. We applied our model of

138 grazing performance from the laboratory experiments (equation 1; in Microsoft Excel) to

139 these temperature data in order to predict how grazing performance might change under each

140 scenario.

\section{Results}

\section{$142 \quad 3.1$ Grazing changes with temperature}

143 The shape of the relationship between grazing rates and temperature was strongly unimodal.

144 Thus, fitting a non-linear (negative quadratic) curve to our laboratory data showed a strong

145 relationship $\left(r^{2}=0.99\right)$ in which peak grazing performance (quadratic maximum) occurred at

$14629.5^{\circ} \mathrm{C}$ (Equation 1; Fig. 1). This model predicts a 70\% decrease in grazing performance at

147 our maximum temperature $\left(38^{\circ} \mathrm{C}\right)$ compared with peak grazing at $29.5^{\circ} \mathrm{C}$, and a $41 \%$

148 decrease at our minimum temperature $\left(23^{\circ} \mathrm{C}\right.$; Fig. 1$)$. Solving this quadratic equation for zero

149 suggests grazing would cease at $19.3^{\circ} \mathrm{C}$ and $39.6^{\circ} \mathrm{C}$ (Fig. 1). 


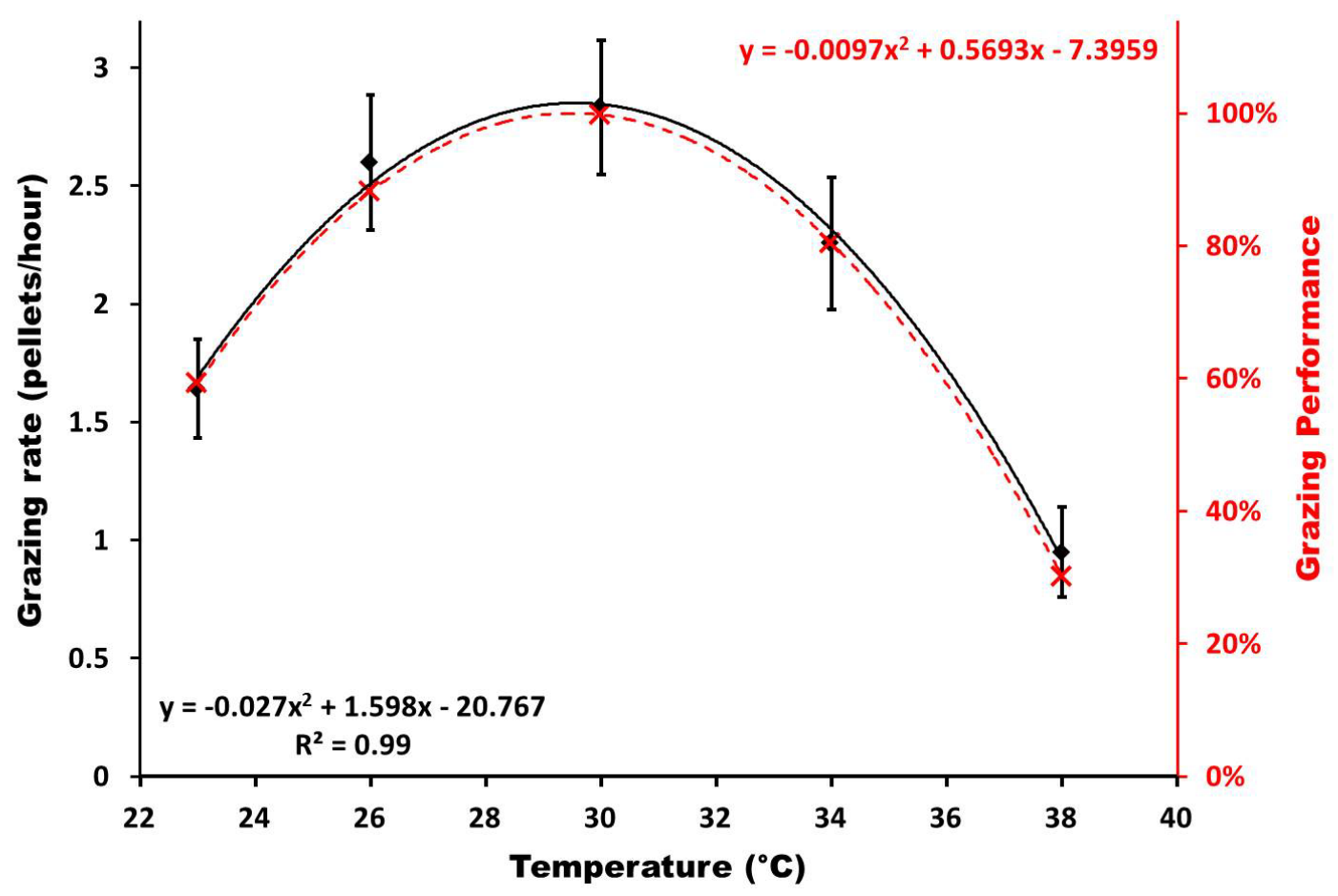

150

Figure 1. Grazing rate and relative grazing performance for hermit crabs at each experimental temperature. Left axis represents measured grazing rates (mean, SE) with negative quadratic fit-line (black). Right axis represents calculated grazing performance compared with peak at $29.5^{\circ} \mathrm{C}$ (based on black quadratic model). Equation for red fit-line (relative grazing performance) is used in modelling future effects of temperature on grazing performance throughout the yellow-footed hermit crab's Indo-Pacific distribution.

Equation 1:

Grazing performance

$$
=\left(\left(-9.651 \times 10^{-3}\right) \times S S T^{2}\right)+\left(\left(569.317 \times 10^{-3}\right) \times S S T\right)-7.396
$$

\subsection{Predicting changes in grazing performance under future climate warming}

Applying this equation for temperature data from 1981 to 2010 across the full range of

C. virescens predicts that grazing is highest in the tropics and declines towards temperate regions (Fig. 2a,b). Under both future warming scenarios, grazing performance is predicted to decrease slightly in tropical seas (max decrease: -18\%) during the warmer months in each hemisphere. The largest and most widespread declines will occur during summer under the more extreme RCP 8.5 scenario (Fig. 2e,f). However, in both scenarios examined, less than 

expected to increase substantially (max increase: $+56 \%$ ) at higher latitudes (Fig. 2c-f).

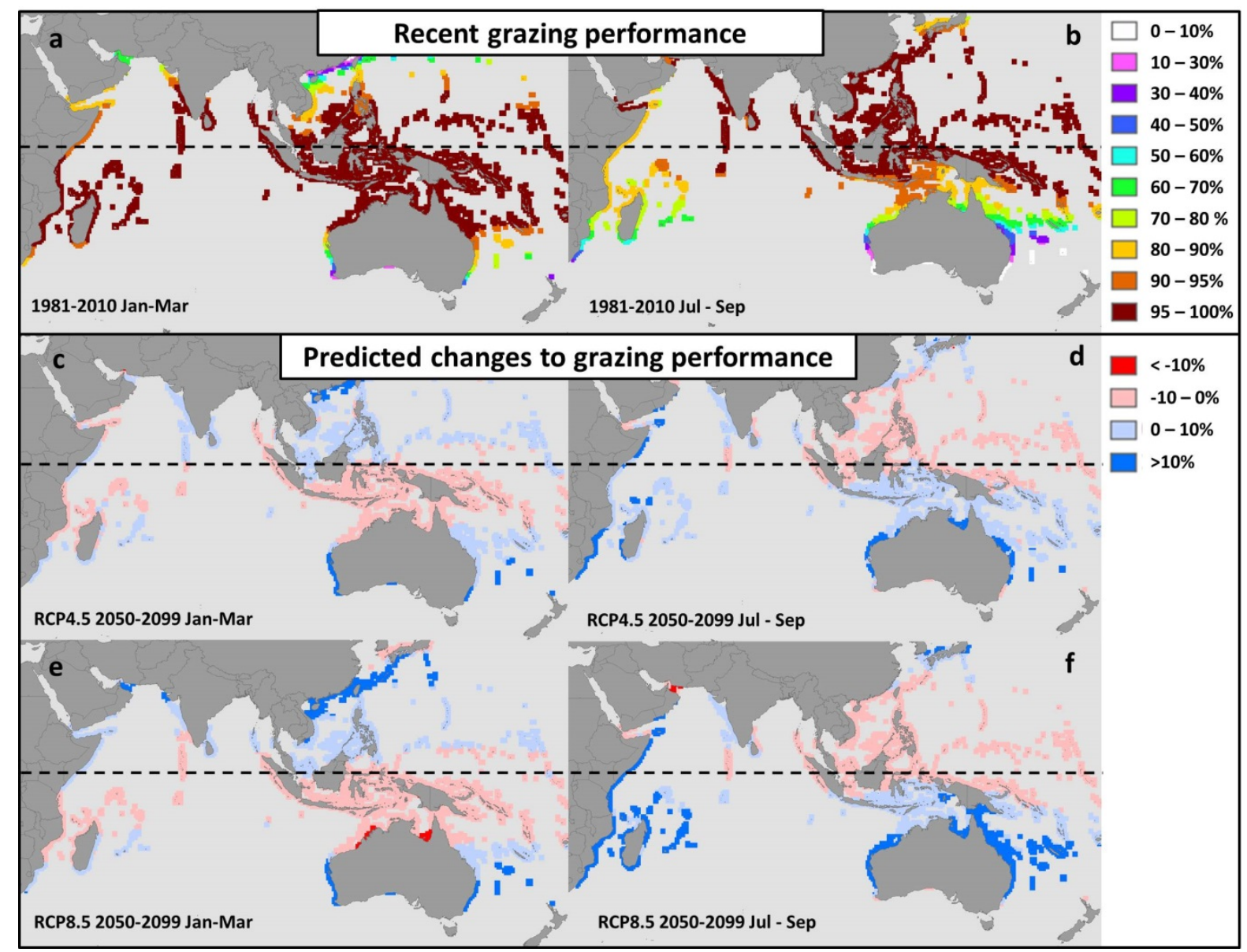

Figure 2 Estimates of grazing performance throughout the range of the hermit crab between 1981 - 2010 (top) and change in grazing performance between 2050 - 2099 under two climate scenarios (RCP 4.5: middle, and RCP 8.5; bottom). Two periods are represented January to March (JFM; left column) and July to September (JAS; right column). Red colours represent a decrease and blue colours represent an increase in grazing performance (2050-2099). Dashed line represents the equator. Note: colour bands are not equally sized.

181 Current grazing is near peak performance (i.e. $>95 \%$ of maximal feeding rate) in many parts of the present day distribution (Fig 2a,b \& 3b). Under all warming scenarios, mean grazing 
performance is likely to increase from approximately 90\% between 1981 and 2010 to a

184 maximum of $93.9 \%$ under the RCP8.5 scenario in JAS (Fig. 3a). Grazing performance is 185 expected to increase across more than half of the distribution in all but one case (RCP8.5

186 JFM), which is expected to experience increases over only $45 \%$ of the distribution. At the 187 other extreme, grazing performance is expected to increase across $68 \%$ of the distribution 188 under RCP4.5 in the JAS period (Fig. 3c). 

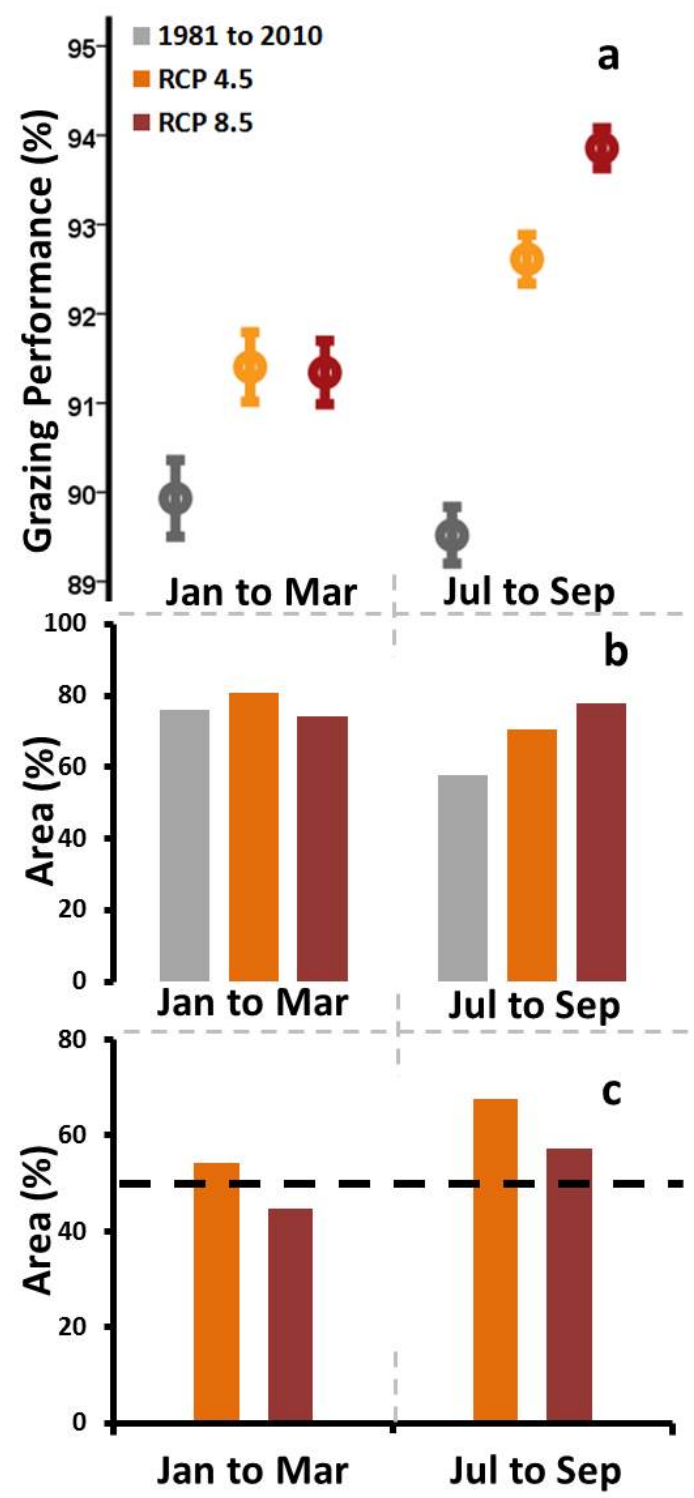

193 Figure 3. Changes in grazing performance under each scenario. a) Grazing performance 194 (mean, SE) under each scenario and time period; b) Area (\% of total area within current 195 distribution) expected to have $>95 \%$ grazing performance under each scenario; c) Area (\%) 196 that is expected to see an increase in grazing performance (positive change) between 2050 197 and 2099 compared with 1981 to 2010 levels. Bars above the 50\% mark (dashed line) show scenarios under which more than half the area will increase in grazing performance. 
Here we demonstrate that rising sea temperatures may trigger asymmetrical changes to

202

203 grazing performance throughout the Indo-Pacific. Grazing by the model species $(C$. virescens) may increase on average across the full range, but with notable differences between the tropics and higher latitudes. Grazing performance for $C$. virescens under both RCP 4.5 and RCP 8.5 will likely decrease marginally in the tropics (generally $<10 \%$, max $18 \%$ ), but over a reasonably large area. In contrast to tropical reefs, the model predicts an increase in grazing performance year-round at higher latitudes, with larger changes expected than in the tropics (up to 56\%). Intertidal and subtidal mesograzers (including small crustaceans) exert strong control over algal biomass across rocky and coral habitats globally (Poore et al., 2012). This suggests that the changes in grazing performance we predict for C. virescens may play some role in structuring reef habitat in the future. However, should these predictions be representative of similar changes in other taxa, then compounding effects could be considerable. Macrograzers exert a stronger effect on algal growth than mesograzers (Poore et al., 2012) and our findings appear to align with thermal responses (e.g. altered consumption and/or distribution with temperature) in other taxa that are better known for their functions as ecosystem engineers (urchins, parrotfishes, etc. (Bennett et al., 2015, Dillon et al., 2010, Lemoine \& Burkepile, 2012)). Thus, if the asymmetrical shifts in grazing performance that we predict for the model species are indicative of similar changes in other consumers, there is potential for broad ecological implications in coastal ecosystems as sea temperatures rise.

The temperature preference of $C$. virescens as estimated from its natural range coincide with those temperatures where it grazes most efficiently. C. virescens reached peak grazing performance at $29.5^{\circ} \mathrm{C}$ with relative grazing decreasing predictably as temperatures moved 
away from this maximum, possibly reaching zero at approximately $19.3^{\circ} \mathrm{C}$ and $39.6^{\circ} \mathrm{C}$. Other tropical taxa show similar trends, whereby consumption rates tend to reach a maximum between $26^{\circ} \mathrm{C}$ and $30^{\circ} \mathrm{C}$ and decline beyond $30^{\circ} \mathrm{C}$ (Lemoine \& Burkepile, 2012, Smith, 2008). The preferred temperature range for $C$. virescens (based on $>2700$ field observations (Aquamaps, 2018, Palomares \& Pauly, 2018)) lies between $24.1^{\circ} \mathrm{C}$ and $29.3^{\circ} \mathrm{C}$ (Palomares \& Pauly, 2018) and species distribution modelling shows low likelihood of occurrence (generally $<30 \%$ ) in areas where winter temperatures average below $19^{\circ} \mathrm{C}$ (Aquamaps, 2018, Palomares \& Pauly, 2018, Reynolds et al., 2002). Thus in a broad sense, the observed range of $C$. virescens reflects those temperatures at which its grazing is maximised.

Range shifts of grazers toward higher latitudes, generally driven by rising temperatures, can have significant consequences for the functioning of ecosystems through altered grazing regimes (Ling et al., 2009, Vergés et al., 2016, Vergés et al., 2014b). Our finding that grazing performance also depends on temperature suggests that models of range shifts should also consider animal performance under local thermal regimes. We show a likely increase in grazing at higher latitudes for the model species, and species distribution modelling for 2100 (Aquamaps, 2018, Palomares \& Pauly, 2018) suggests higher probabilities of occurrence for C. virescens in regions where we predict higher grazing performance (e.g. warm temperate regions). A range shift driven by warming that saw an increasing abundance of grazers at higher latitudes may interact with the effect of warming on grazing performance to synergistically increase grazing rates. These findings are also consistent with observed range shifts in other species (Bennett et al., 2015, Dillon et al., 2010, Hoegh-Guldberg et al., 2007, Vergés et al., 2014a). As distribution and disturbance effect models move from predicting pure abundance changes toward functional measures (Bonebrake et al., 2018, Mouillot et al., 2013, Murray et al., 2018, Sunday et al., 2015), we therefore should consider the effects of temperature on animal performance. This suggests that measuring the grazing performance of 
ecosystem engineers (e.g. urchins, parrotfish, rabbitfish (Vergés et al., 2014a)), in parallel

with further studies adding to the limited literature on mesograzer responses to changing estimate the full effects of herbivore range shifts on ecosystem function.

Temperature increases will also trigger a broader suite of changes to reef systems that may affect habitat structure and stability beyond the consumer performance model we present. For example, habitat formers themselves (e.g. algae (O'Connor, 2009), corals (Lough et al., 2018), seagrass (Hernán et al., 2017)) will also respond to warming by altering growth rates, abundance, and ranges. These changes may dampen or exacerbate the effect of altered grazing performance depending on the region, direction, and rate of change (O'Connor, 2009). While there are also broader, indirect effects associated with an abundance of grazers in algal-dominated communities (e.g. potential concurrent changes in predator abundance), when considering the direct effects of grazing across taxa it is generally accepted that this function is less beneficial to ecosystem stability in temperate reefs than in coral systems (e.g. Mumby et al., 2006, Wernberg et al., 2016).

We assessed the effect of temperature on grazing performance in the absence of other stressors or influencing factors and based on short-term exposures in the laboratory. As a result, the findings we present are likely indicative of the nature of trends we would expect to arise from real-world temperature increases, but not the magnitude of them. There are likely to be interacting effects from multiple stressors (e.g. Boyd et al., 2015, Hughes et al., 2018, Scartazza et al., 2017) under future climate scenarios which may confound the effect of temperature (either exacerbating or dampening the magnitude). Thus, we suggest that future studies would do well to investigate the effect of interacting stressors (e.g. acidification, prevalence of disease; Cao et al., 2018) and interacting responses (e.g. concurrent changes in producer biomass, algal growth rates) on important ecological processes such as grazing. We 
also acknowledge that our crabs were collected from a single location, which may not account for different temperature sensitivities of individuals from other regions. Variation in thermal tolerances among geographically separate populations has been found in marine invertebrates (Sorte et al., 2011). The amount of variation, however, varies among taxa, from substantial to trivial differences (Sorte et al., 2011). Given that no information is available about geographic variation in tolerances for hermit crabs, we simply point out that variability in temperature sensitivity for crabs between regions may alter the response curve. This would result in a different magnitude of change (and direction for areas close to the peak) in grazing performance than we present here. Notwithstanding any shortcomings of laboratory experiments and modelling, there is supporting evidence from other field studies and models, suggesting that the type of functional responses presented here are plausible. We therefore posit that our results provide a useful conceptual advance of how climate change may alter pivotal ecological functions, represented here by subtidal grazing in the tropical to warmtemperate Indo-Pacific region.

\section{Acknowledgements}

We thank J. Chapman for laboratory assistance. This work was supported by the Australian Research Council through a Discovery Project to RMC and TAS (DP150102271) and a Discovery Early Career Researcher Award to CJB (DE160101207).

\section{References}

Aquamaps (2018) Computer generated distribution maps for Clibanarius virescens (coastal hermit crabs), with modelled year 2100 native range map based on IPCC A2 emissions scenario. In: Aquamaps. pp Page, www.aquamaps.org. Accessed 19 April 2018.

Bellwood DR, Hoey AS, Choat JH (2003) Limited functional redundancy in high diversity systems: resilience and ecosystem function on coral reefs. Ecology letters, 6, 281-285.

Bennett S, Wernberg T, Harvey ES, Santana-Garcon J, Saunders BJ (2015) Tropical herbivores provide resilience to a climate-mediated phase shift on temperate reefs. Ecology letters, 18, 714723. 
Bonebrake TC, Brown CJ, Bell JD et al. (2018) Managing consequences of climate-driven species redistribution requires integration of ecology, conservation and social science. Biological Reviews, 93, 284-305.

Boyd PW, Lennartz ST, Glover DM, Doney SC (2015) Biological ramifications of climate-changemediated oceanic multi-stressors. Nature Climate Change, 5, 71-79.

Boyer KE, Fong P, Armitage AR, Cohen RA (2004) Elevated nutrient content of tropical macroalgae increases rates of herbivory in coral, seagrass, and mangrove habitats. Coral Reefs, 23, 530538.

Briffa M, Bridger D, Biro PA (2013) How does temperature affect behaviour? Multilevel analysis of plasticity, personality and predictability in hermit crabs. Animal Behaviour, 86, 47-54.

Brown JH, Gillooly JF, Allen AP, Savage VM, West GB (2004) Toward a metabolic theory of ecology. Ecology, 85, 1771-1789.

Cao R, Wang Q, Yang D et al. (2018) CO2-induced ocean acidification impairs the immune function of the Pacific oyster against Vibrio splendidus challenge: An integrated study from a cellular and proteomic perspective. Science of the Total Environment, 625, 1574-1583.

Dillon ME, Wang G, Huey RB (2010) Global metabolic impacts of recent climate warming. Nature, 467, 704-706.

Dunbar S (2005) Respiratory responses of Clibanarius taeniatus (Kraus, 1843) and Clibanarius virescens (Milne-Edwards, 1848)(Decapoda: Diogenidae) to changes in ambient water temperature. Nauplius, 13, 45-56.

Elner RW (1980) The influence of temperature, sex and chela size in the foraging strategy of the shore crab, Carcinus maenas (L.). Marine \& Freshwater Behaviour \& Phy, 7, 15-24.

Fussmann KE, Schwarzmüller F, Brose U, Jousset A, Rall BC (2014) Ecological stability in response to warming. Nature Climate Change, 4, 206-210.

Goldenberg SU, Nagelkerken I, Marangon E, Bonnet A, Ferreira CM, Connell SD (2018) Ecological complexity buffers the impacts of future climate on marine consumers. Nature Climate Change, 8, 229-233.

Hempson TN, Graham NA, Macneil MA, Hoey AS, Wilson SK (2018) Ecosystem regime shifts disrupt trophic structure. Ecological Applications, 28, 191-200.

Hernán G, Ortega MJ, Gándara AM, Castejón I, Terrados J, Tomas F (2017) Future warmer seas: increased stress and susceptibility to grazing in seedlings of a marine habitat-forming species. Global change biology, 23, 4530-4543.

Hoegh-Guldberg O, Bruno JF (2010) The impact of climate change on the world's marine ecosystems. Science, 328, 1523-1528.

Hoegh-Guldberg O, Mumby PJ, Hooten AJ et al. (2007) Coral reefs under rapid climate change and ocean acidification. Science, 318, 1737-1742.

Hughes BB, Lummis SC, Anderson SC, Kroeker KJ (2018) Unexpected resilience of a seagrass system exposed to global stressors. Global change biology, 24, 224-234.

Hughes TP, Rodrigues MJ, Bellwood DR et al. (2007) Phase shifts, herbivory, and the resilience of coral reefs to climate change. Current Biology, 17, 360-365.

Kraus F (1843) Die siidafrikanischen Crustaceen, Stuttgart.

Kunze J, Anderson D (1979) Functional morphology of the mouthparts and gastric mill in the hermit crabs Clibanarius taeniatus (Milne Edwards), Clibanarius virescens (Krauss), Paguristes squamosus (McCulloch) and Dardanus setifer (Milne-Edwards)(Anomura: Paguridae). Marine and Freshwater Research, 30, 683-722.

Lancaster LT (2016) Widespread range expansions shape latitudinal variation in insect thermal limits. Nature Climate Change, 6, 618-621.

Leidenberger S, De Giovanni R, Kulawik R, Williams AR, Bourlat SJ (2015) Mapping present and future potential distribution patterns for a meso-grazer guild in the Baltic Sea. Journal of biogeography, 42, 241-254. 
Lemoine NP, Burkepile DE (2012) Temperature-induced mismatches between consumption and metabolism reduce consumer fitness. Ecology, 93, 2483-2489.

Lewinsohn C (1982) Researches on the Coast of Somalia. The Shore and the Dune of Sar Uanle: 33. Diogenidae, Paguridae and Coenobitidae (Crustacea Decapoda Paguridea). Monitore Zoologico Italiano. Supplemento, 16, 35-68.

Ling S, Johnson C, Ridgway K, Hobday A, Haddon M (2009) Climate-driven range extension of a sea urchin: inferring future trends by analysis of recent population dynamics. Global change biology, 15, 719-731.

Lough J, Anderson K, Hughes T (2018) Increasing thermal stress for tropical coral reefs: 1871-2017. Scientific reports, 8:6079, 1-8.

Morgan GJ (1988) Variation in a key character in a population of Clibanarius virescens (Krauss, 1843)(Decapoda, Diogenidae). Crustaceana, 55, 317-318.

Moss RH, Edmonds JA, Hibbard KA et al. (2010) The next generation of scenarios for climate change research and assessment. Nature, 463, 747-756.

Mouillot D, Graham NA, Villéger S, Mason NW, Bellwood DR (2013) A functional approach reveals community responses to disturbances. Trends in ecology \& evolution, 28, 167-177.

Mumby PJ, Dahlgren CP, Harborne AR et al. (2006) Fishing, trophic cascades, and the process of grazing on coral reefs. Science, 311, 98-101.

Mumby PJ, Hastings A, Edwards HJ (2007) Thresholds and the resilience of Caribbean coral reefs. Nature, 450, 98-101.

Murray NJ, Keith DA, Bland LM et al. (2018) The role of satellite remote sensing in structured ecosystem risk assessments. Science of the Total Environment, 619-620, 249-257.

Newell R, Branch G (1980) The influence of temperature on the maintenance of metabolic energy balance in marine invertebrates. Advances in marine biology, 17, 329-396.

Noaa/Esrl Physical Sciences Division (2018) NOAA Climate Change Web Portal, https://www.esrl.noaa.gov/psd/ipcc/ocn/. Accessed 19 April 2018, National Oceanic \& Atmospheric Administration.

O'connor MI (2009) Warming strengthens an herbivore-plant interaction. Ecology, 90, 388-398.

Palomares MLD, Pauly D (2018) SeaLifeBase, http://www.sealifebase.org/summary/Clibanariusvirescens.html. Accessed 19 April 2018.

Perez TM, Stroud JT, Feeley KJ (2016) Thermal trouble in the tropics. Science, 351, 1392-1393.

Poloczanska ES, Brown CJ, Sydeman WJ et al. (2013) Global imprint of climate change on marine life. Nature Climate Change, 3, 919-925.

Poore AG, Campbell AH, Coleman RA et al. (2012) Global patterns in the impact of marine herbivores on benthic primary producers. Ecology letters, 15, 912-922.

Rall BC, Vucic-Pestic O, Ehnes RB, Emmerson M, Brose U (2010) Temperature, predator-prey interaction strength and population stability. Global change biology, 16, 2145-2157.

Reynolds RW, Rayner NA, Smith TM, Stokes DC, Wang W (2002) An improved in situ and satellite SST analysis for climate. Journal of climate, 15, 1609-1625.

Scartazza A, Moscatello S, Gavrichkova O et al. (2017) Carbon and nitrogen allocation strategy in Posidonia oceanica is altered by seawater acidification. Science of the Total Environment, 607-608, 954-964.

Smith T (2008) Temperature effects on herbivory for an Indo-Pacific parrotfish in Panamá: implications for coral-algal competition. Coral Reefs, 27, 397-405.

Sorte CJ, Jones SJ, Miller LP (2011) Geographic variation in temperature tolerance as an indicator of potential population responses to climate change. Journal of Experimental Marine Biology and Ecology, 400, 209-217.

Stuart-Smith RD, Edgar GJ, Bates AE (2017) Thermal limits to the geographic distributions of shallowwater marine species. Nature ecology \& evolution, 1, 1846-1852.

Sunday JM, Pecl GT, Frusher S et al. (2015) Species traits and climate velocity explain geographic range shifts in an ocean-warming hotspot. Ecology letters, 18, 944-953. 
Vergés A, Doropoulos C, Malcolm HA et al. (2016) Long-term empirical evidence of ocean warming leading to tropicalization of fish communities, increased herbivory, and loss of kelp. Proceedings of the National Academy of Sciences, 113, 13791-13796.

Vergés A, Steinberg PD, Hay ME et al. (2014a) The tropicalization of temperate marine ecosystems: climate-mediated changes in herbivory and community phase shifts. Proc. R. Soc. B, 281:20140846, 1-10.

Vergés A, Tomas F, Cebrian E et al. (2014b) Tropical rabbitfish and the deforestation of a warming temperate sea. Journal of Ecology, 102, 1518-1527.

Wernberg T, Bennett S, Babcock RC et al. (2016) Climate-driven regime shift of a temperate marine ecosystem. Science, 353, 169-172.

World Sea Temperature (2018) Global Sea Temperature, https://www.seatemperature.org/. Accessed 24 April 2018.

Worm B, Lotze HK (2006) Effects of eutrophication, grazing, and algal blooms on rocky shores. Limnology and oceanography, 51, 569-579. 